\title{
C-glycosyl flavonoids-rich extract of Dipcadi erythraeum Webb \& Berthel. bulbs: Phytochemical and anticancer evaluations
}

\author{
Mona M. Marzouk ${ }^{1}$, Ahmed Elkhateeb ${ }^{1}$, Rasha R. Abdel Latif ${ }^{1}$, El-Sayed S. Abdel-Hameed ${ }^{2}$, Salwa A. Kawashty ${ }^{1}$, Sameh R. \\ Hussein $^{1 *}$ \\ ${ }^{1}$ Phytochemistry and Plant Systematics Department, National Research Centre, Giza, Egypt. \\ ${ }^{2}$ Laboratory of Medicinal Chemistry, Theodor Bilharz Institute, Giza, Egypt.
}

\begin{tabular}{l}
\hline ARTICLE INFO \\
\hline Received on: 01/11/2018 \\
Accepted on: $29 / 12 / 2018$ \\
Available online: $05 / 06 / 2019$
\end{tabular}

\section{Key words:}

Dipcadi erythraeum,

$C$-glycosyl flavonoids, LC-

ESI-MS, cytotoxic activity.

\begin{abstract}
Dipcadi erythraeum Webb \& Berthel. is a wild edible species belonging to family Asparagaceae and commonly used in folk medicine. The D. erythraeum bulbs extract was subjected to chemical investigation using Liquid Chromatography-Electrospray Ionization Mass Spectrometry (LC-ESI-MS) technique to identify its polar active constituents and evaluated against four human carcinoma cell lines; MCF7, HEPG2, A549, and HCT116. The $D$. erythraeum bulbs extract revealed 22 phenolic compounds characterized for the first time from the studied species, 14 of them were identified as $C$-glycosyl flavonoids. Moreover, the studied extract showed moderate activity against MCF7 and HCT116 at $100 \mu \mathrm{g} / \mathrm{ml}$ with cell viability of $43.6 \%$ and $48.4 \%$, respectively. From the chemotaxonomic point of view, the presence of $C$-glycosyl flavonoids supported that $D$. erythraeum has a closer relationship with the species of Asparagaceae family than Liliaceae.
\end{abstract}

\section{INTRODUCTION}

The genus Dipcadi is recently belonging to the subfamily Scilloideae of the family Asparagaceae. It is reported mainly from Africa, peninsular India, Madagascar, and neighboring Pakistan. Ten species of this genus are reported, of which D. erythraeum Webb \& Berthel. is distributed in India as well as in different tropical regions of the world such as the Canary Islands, Arabia, Egypt, and Saudi Arabia (Boulos, 2009).

Dipcadi erythraeum [Syn. Dipcadi unicolor (Stocks) Baker, Uropetalum unicolor, Hooker's, Ornithogalum erythraeum (Webb \& Berthel.) J. C. Manning \& Goldblatt, Uropetalon erythraeum (Webb \& Berthel.) Boiss.] is observed in rocky and gravelly habitats where rainwater collects for some days. The leaves are narrowly linear, while the flowers are greenish in color.

\footnotetext{
${ }^{*}$ Corresponding Author

Sameh Reda Hussein, Phytochemistry and Plant Systematics Department, National Research Centre, Giza, Egypt.

E-mail: sameh_reda@hotmail.com
}

Flowers and fruits appear during the months of August-September (Bhandari, 1990).

Dipcadi erythraeum is a medicinal plant with great folk uses. The bulbs and capsules are eaten raw during the famine (Jongbloed et al., 2000; Mandaville, 1990). The leaves are laxative and used as an ointment for wounds (Moussaid et al., 2013), while the whole plant is used for a cough, biliousness, diabetes, urinary and discharge. Phytochemical screening of Dipcadi species revealed the presence of tannins, alkaloids, flavonoids, and saponins (Abdulkareem et al., 2014; Adly et al., 2015; Ali, 2005). El-Shabrawy et al. (2016) reported the isolation of two flavonol aglycones (kaempferol and quercetin), one flavonol glycoside (quercetin 3-O-rutinoside-7$O$ - $\alpha$-rhamnopyranoside), and four $C$-glycosyl flavones (vitexin, isovitexin, orientin, and isoorientin) from the defatted aqueous methanol extract of $D$. erythraeum whole plant.

There are no biological activities reported for $D$. erythraeum, therefore, the objective of the present study is to further our knowledge about its phytochemical constituent using Liquid Chromatography-Electrospray Ionization Mass Spectrometry (LCESI-MS) and evaluate its cytotoxic activity against breast (MCF7), hepatocellular (HEPG2), lung (A549), and colon (HCT116) cell lines. 


\section{EXPERIMENTAL}

\section{Plant material and extraction}

Dipcadi erythraeum was collected $120 \mathrm{~km}$ CairoAlexandria desert road, in March 2017 and identified by M. ElShabrawy. A voucher specimen (s.n. MS6) was deposited in the herbarium of the National Research Center (CAIRC). The bulbs were dried and grinded, then extracted three times with $70 \%$ $\mathrm{MeOH} / \mathrm{H}_{2} \mathrm{O}$ (Mabry et al., 1970). The solvent was evaporated under reduced pressure at $50^{\circ} \mathrm{C}$ and then the dried extract was defatted with petroleum ether.

\section{LC-ESI-MS analysis}

Dipcadi erythraeum aqueous methanol extract was analyzed by LC-ESI-MS system [High Performance Liquid Chromatography (Waters Alliance 2695) and mass spectrometry (Waters 3100)] according to the methods of Hussein et al. (2018). Known peaks were identified by comparing their retention time and mass spectrum with the flavonoid standards (95\% purity; UV, Nuclear Magnetic Resonance) which were obtained from our research group (Phytochemical and Plant Systematic Department, NRC) (El-Shabrawy et al., 2016; El-Sherei et al., 2018; Hussein et al., 2017, 2018; Ibrahim et al., 2013; Marzouk et al., 2010). Other peaks were tentatively identified by comparing the mass spectrum with the literature.

\section{Cell culture and sample treatment}

The investigated human carcinoma cell lines were breast (MCF7), hepatocellular (HEPG2), lung (A549), and colon (HCT116). They were purchased from American Tissue Culture Collection. HEPG2, MCF7, and HCT116 cells lines were cultured in RPMI 1640 medium, while A549 cell line was cultured in DMEM media. Media and cell culture preparations and treatments in addition to the in vitro cytotoxic activity of the plant extract were measured and followed the same method of Ibrahim et al. (2013).

\section{RESULTS AND DISCUSSION}

\section{Identification of phenolics using LC-ESI-MS analysis}

Twenty-two compounds were identified in the bulbs extract of D. erythraeum (Fig. 1, Table 1), all of them were characterized for the first time in the studied species.

Peak $2(m / z 195)$ was characterized as gluconic acid. Its spectrum showed a fragment ion at $\mathrm{m} / \mathrm{z} 129$ which corresponds to the loss of $\mathrm{H}_{2} \mathrm{O}$ and $\mathrm{CO}_{2}$ molecules [M-H-CO $\left.-\mathrm{CH}_{2} \mathrm{O}\right]^{-}$(Felipe et al., 2014). Peak (3) at $\mathrm{m} / \mathrm{z} 335$ showed a fragment ion at $\mathrm{m} / \mathrm{z} 173$ $[\mathrm{M}-162-\mathrm{H}]^{-}$, after the loss of hexose unit, indicative for shikimic acid which showed other two fragments after the loss of $\mathrm{H}_{2} \mathrm{O}$ molecules; $m / z 155\left[\mathrm{M}-162-\mathrm{H}-\mathrm{H}_{2} \mathrm{O}\right]^{-}$and 137 [M-162- $\left.\mathrm{H}-2 \mathrm{H}_{2} \mathrm{O}\right]^{-}$. Accordingly, compound $\mathbf{3}$ was tentatively identified as shikimic acid hexoside (Spínola et al., 2015). Peak (4) showed [M-H] $]^{-}$ion at $\mathrm{m} / \mathrm{z} 487$ and produced fragments at $\mathrm{m} / \mathrm{z} 325$ [M-H-hexose] (coumaric acid hexoside), 163 [M-H-2hexose $]^{-}$(coumaric acid), and $m / z 119$ [M-H-2hexose-COOH] $]^{-}$(decarboxylated coumaric acid). Thus, compound $\mathbf{4}$ was tentatively identified as coumaric acid dihexoside (Simirgiotis et al., 2015). Peak (5) showed a molecular ion at $\mathrm{m} / \mathrm{z} 503$ and revealed fragments at $\mathrm{m} / \mathrm{z} 341$ [M-H-

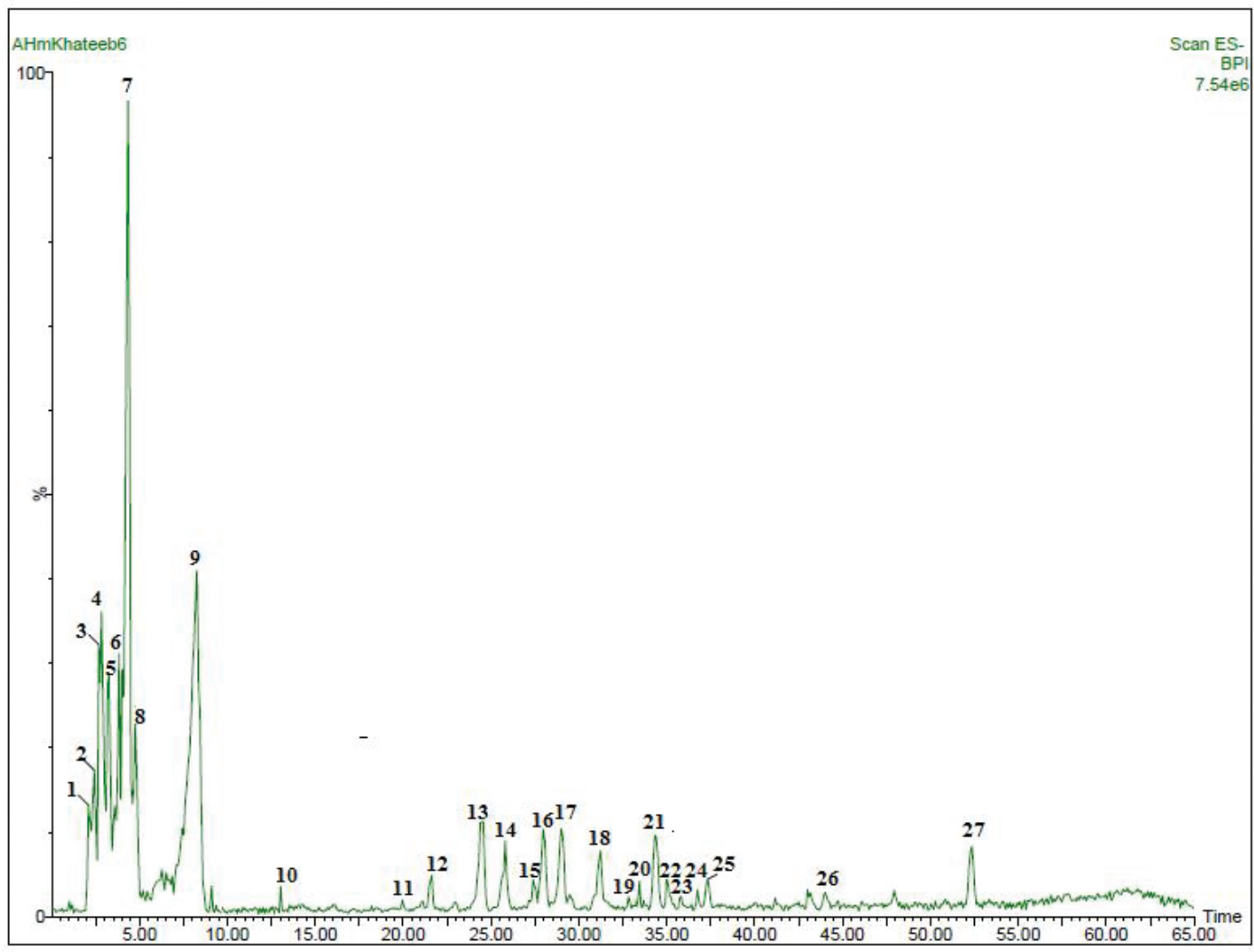

Figure 1. LC-ESI-MS chromatogram of D. erythraeum bulbs. 
Table 1. Tentative identificatiotn of chemical compounds in D. erythraeum bulbs.

\begin{tabular}{|c|c|c|c|c|c|}
\hline No. & $R t$ (min) & M & {$[\mathbf{M}-\mathbf{H}]^{-}$} & $m / z$ fragments & Tentative identification \\
\hline 1 & 2.09 & 306 & 305 & $289,273,175,159$ & Unknown \\
\hline 2 & 2.42 & 196 & 195 & $177,159,129$ & Gluconic acid \\
\hline 3 & 2.67 & 336 & 335 & $173,155,137,93$ & Shikimic acid hexoside \\
\hline 4 & 2.84 & 488 & 487 & $325,163,119$ & Coumaricaciddihexoside \\
\hline 5 & 3.25 & 504 & 503 & $341,179,135$ & Caffeicaciddihexoside \\
\hline 6 & 3.84 & 317 & 316 & 171,128 & Unknown \\
\hline 7 & 4.34 & 196 & 195 & 80,96 & Unknown \\
\hline 8 & 4.76 & 192 & 191 & $173,128,85$ & Quinic acid \\
\hline 9 & 8.3 & 422 & 421 & $337,173,113$ & Malonylcoumaroylquinic acid \\
\hline 10 & 13.03 & 356 & 355 & & Ferulic acid hexoside \\
\hline 11 & 19.82 & 610 & 609 & $447,357,327$ & Isoorientin-7-O- $\beta$-glucopyranoside (lutonarin)* \\
\hline 12 & 21.5 & 562 & 561 & 470 & Apigenin 6,8-di- $C$-rhamnoside* \\
\hline 13 & 24.55 & 594 & 593 & 503,473 & Apigenin 6,8 -di- $C$-glucoside* \\
\hline 14 & 25.8 & 572 & 571 & $481,459,257$ & Unknown \\
\hline 15 & 27.47 & 490 & 489 & $447,429,327$ & Isoorientin $\mathrm{X}^{\prime \prime}-O$-acetyl \\
\hline 16 & 27.9 & 606 & 605 & $503,473,443$ & Apigenin 6-C-pentoside-8- $C$-hexoside $\mathrm{X}^{\prime \prime}$ - $O$-acetyl \\
\hline 17 & 28.9 & 639 & 638 & 506,302 & Delphinidin- $O$-hexoside $\mathrm{X}^{\prime \prime}-O$-acetyl- $O$-pentoside \\
\hline 18 & 31.2 & 580 & 579 & 489,459 & $\begin{array}{l}\text { Luteolin } 6-C \text { - } \beta \text {-glucopyranoside- } 8 \text { - } C \text { - } \alpha \text {-arabinopyranoside } \\
\text { (carlinoside)* }\end{array}$ \\
\hline 19 & 33.3 & 578 & 577 & 457 & $\begin{array}{l}\text { Apigenin } 6 \text { - } C \text { - } \beta \text {-glucopyranoside- } 8-C \text { - } \alpha \text {-rhamnopyranoside } \\
\text { (violanthin)* }\end{array}$ \\
\hline 20 & 33.48 & 678 & 677 & $533,473,443,383,353$ & Apigenin 6,8-di- $C$-pentoside- $O$-rhamnoside \\
\hline 21 & 34.4 & 564 & 563 & $503,473,443$ & Apigenin 6- $C$-hexoside-8- $C$-pentoside \\
\hline 22 & 35.15 & 594 & 593 & $533,503,473$ & Luteolin- $O$-methyl ether6- $C$-pentoside-8- $C$-hexoside \\
\hline 23 & 35.8 & 548 & 547 & 478 & Apigenin 6- $C$-pentoside-8- $C$-rhamnoside \\
\hline 24 & 36.74 & 694 & 693 & 547,478 & Apigenin 6-C-pentoside-8- $C$-rhamnose- $O$-rhamnoside \\
\hline 25 & 37.4 & 578 & 577 & $487,473,457$ & $\begin{array}{l}\text { Apigenin } 6-C \text { - } \alpha \text {-rhamnopyranoside- } 8-C-\beta \text { - } \\
\text { glucopyranoside(isoviolanthin)* }\end{array}$ \\
\hline 26 & 41.4 & 754 & 753 & $591,501,487,471$ & $\begin{array}{l}\text { Apigenin- } O \text {-methyl ether-6- } C \text {-hexoside- } 8 \text { - } C \text {-rhamnoside- } \\
O \text {-hexoside }\end{array}$ \\
\hline 27 & 52.36 & 1052 & 1051 & 869 & Unknown \\
\hline
\end{tabular}

*Compounds identified by comparing their retention times and mass spectrum with the authentic.

${ }^{s}$ Compounds identified based on the mass spectral data cited in the literature.

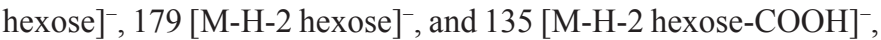
indicating the presence of caffeic acid di-hexoside (Simirgiotis et al., 2015). Compound (8) at $\mathrm{m} / \mathrm{z} 191$ was existing as quinic acid, confirmed by the presence of the fragment ion at $\mathrm{m} / \mathrm{z} 127$ [M-H$\left.\mathrm{CO}-2 \mathrm{H}_{2} \mathrm{O}\right]^{-}$(Taamalli et al., 2015).

Peak (9) at $\mathrm{m} / \mathrm{z} 421$ revealed the fragmentation pattern of coumaroyl quinic acid $(\mathrm{m} / \mathrm{z} 337,191,173,163$, and 119) (Marzouk et al., 2018) with an extra 84 amu, suggestive for a malonyl group. Therefore, compound 9 was considered as malonylcoumaroyl quinic acid. Peak (10) showed a molecular ion at $\mathrm{m} / \mathrm{z} 355$ and revealed fragments at $\mathrm{m} / \mathrm{z} 193$ [M-H-hexose] and $149[\mathrm{M}-\mathrm{H}-\text { hexose-COOH}]^{-}$, indicating the presence of ferulic acid hexoside (Simirgiotis et al., 2015). Peak (11) with a molecular anion at $\mathrm{m} / \mathrm{z} 609$ showed a fragment ion at $\mathrm{m} / \mathrm{z} 447$ after the loss of a dehydrated hexose unit [M-162-H]-, attached as $O$-substitution of the $\mathrm{C}$-glycosyl flavone structure. The fragment ions at $\mathrm{m} / z 327[447-120-\mathrm{H}]^{-}$and at $\mathrm{m} / \mathrm{z} 357$ [447-90$\mathrm{H}]^{-}$confirmed the characteristic isoorientin ion. Therefore, peak
11 assigned as isoorientin-7- $O$-hexoside. In comparison with standards, compound $\mathbf{1 1}$ was identified as isoorientin-7- $O-\beta$ glucopyranoside (lutonarin) (El-Sherei et al., 2018).

Compound (12) showed a molecular anion at $\mathrm{m} / \mathrm{z} 562$ and exhibited losses of (-90) which appeared at $\mathrm{m} / \mathrm{z} 472$. It was readily assigned as apigenin-6, 8-di- $C$-rhamnoside, in comparison with a standard. Likewise, apigenin-6, 8-di- $C$-glucoside was identified for peak (13) at $\mathrm{m} / \mathrm{z} 593$ and confirmed by its losses of (-90 amu) and (-120 amu) appearing at $\mathrm{m} / \mathrm{z} 503$ and 473.

Peak (15) showed typical fragments of isoorientin $\left(\mathrm{m} / z 327[\mathrm{M}-120-\mathrm{H}]^{-}\right.$and $\left.m / z 357[\mathrm{M}-90-\mathrm{H}]^{-}\right)$with an extra $42 \mathrm{amu}$, suggestive for an acetyl group connected to a glucose moiety and identified as isoorientin $\mathrm{X}^{\prime \prime}$ - $O$-acetyl. Moreover, peak (16) has a molecular ion at $m / z 605$ and showed fragmentation pattern of apigenin 6- $C$-pentoside-8- $C$-hexoside with an extra $42 \mathrm{amu}$ indicative for an acetyl group connected to either hexose or pentose moieties as revealed from its $-120 \mathrm{amu}$ and $-90 \mathrm{amu}$ losses appearing at $m / z 443$ and 473, respectively, in addition to 
-60 amu loss for a $C$-pentoside appearing at $m / z 503[\mathrm{M}-60-\mathrm{H}]^{-}$ corresponding to a $C$-linked pentose. Pentose moiety is suggested to attach at the C-6 position as evident from $m / z 503[\mathrm{M}-60-\mathrm{H}]^{-}$ appearing at higher intensity relative to $m / z 443[\mathrm{M}-120-\mathrm{H}]^{-}$and $473[\mathrm{M}-90-\mathrm{H}]^{-}$(Geiger and Markham, 1986). Therefore, peak 16 was identified as apigenin-6- $C$-pentoside-8- $C$-hexoside $\mathrm{X}^{\prime \prime}-O$ acetyl. Di- $C$-glycosyl apigenin acetate derivatives were reported previously from some monocotyledon members (Williams, 1975).

Peak (17) with $m / z 638$ showed a fragment ion at $m / z$ $506[\mathrm{M}-132-\mathrm{H}]^{-}$, after the loss of pentose unit and indicative for delphinidin- $O$-hexoside with an extra 42 amu indicative for an acetyl group connected to the hexose moiety. Another fragment was observed at $\mathrm{m} / \mathrm{z} 302$ for delphinidin aglycone, thus compounds $\mathbf{1 7}$ was tentatively identified as delphinidin- $O$-hexoside $\mathrm{X}^{\prime \prime}-O$-acetyl$O$-pentoside. Delphinidin di-acetyl di-glycoside was reported before from the bulbs of other member of family Hyacinthaceae (Dias et al., 2003).

On the bases of retention time and fragmentation pattern of standards, compound $\mathbf{1 8}$ with $\mathrm{m} / z 579$ is identified as luteolin 6- $C$ - $\beta$-glucopyranoside- $8-C$ - $\alpha$-arabinopyranoside (carlinoside) (El-Sherei et al., 2018), confirmed by three fragment ions at $\mathrm{m} / \mathrm{z}$ 519 [M-60-H] $]^{-}, m / z 489$ [M-90-H] $]^{-}$, and $m / z 459$ [M-120-H].

Isomer peaks (19) and (25) showed the same molecular ion peak at $\mathrm{m} / \mathrm{z} 577$ and displayed the same fragment ions at $m / z 487[\mathrm{M}-90-\mathrm{H}]^{-}$and $m / z 457[\mathrm{M}-120-\mathrm{H}]^{-}$indicative for a $C$-hexose unit. Isomers difference was founded on the intensity of $m / z 457$ [M-120-H] $]^{-}$fragment for compound 19, it appeared as a base peak suggesting the attachment of the deoxyhexosyl moiety at the C-6 (Farag et al., 2016). In comparison with standards, compounds 19 and 25 were identified as apigenin 6- $C$ - $\beta$-glucopyranoside- $8-C$ - $\alpha$-rhamnopyranoside (violanthin) and apigenin 6- $C$ - $\alpha$-rhamnopyranoside- 8 - $C$ - $\beta$-glucopyranoside (isoviolanthin), respectively (El-Sherei et al., 2018).

Peak (20) at $m / z 677$ showed a fragment ion at $m / z 533$, after the loss of a dehydrated rhamnose unit [M-146-H] $]^{-}$, attached as $O$-substitution of the flavone di $C$-glycoside structure $(\mathrm{m} / \mathrm{z}$ $533)$. Further fragmentation pattern of $\mathrm{m} / \mathrm{z} 533$ was revealed as $\mathrm{m} / z 473[\mathrm{M}-60-\mathrm{H}]^{-}$and $443[\mathrm{M}-90-\mathrm{H}]^{-}$, indicating the loss for $C$-pentoside. Therefore, compound $\mathbf{2 0}$ was identified as apigenin 6, 8-di- $C$-pentoside- $O$-rhamnoside.

Peak (21) at $m / z 563$ showed fragmentation pattern of flavone- $C$-hexoside as revealed from its ( $-120 \mathrm{amu}$ ) and ( $-90 \mathrm{amu})$ losses appearing at $\mathrm{m} / \mathrm{z} 443$ and 473, respectively, in addition to (-60 amu) loss for a $C$-pentoside appearing at $m / z 503$ [M-60-H] corresponding to a $C$-linked pentose. Hexose moiety is suggested to attach at the C-6 position as evident from $m / z 443$ [M-120-H] appearing as base peak relative to pentose (Geiger and Markham, 1986) and was identified as apigenin-6- $C$-hexoside-8- $C$-pentoside.

Peak (23) at $\mathrm{m} / \mathrm{z} 547$ revealed a fragment ion at $\mathrm{m} / \mathrm{z} 487$ after the loss of -60 amu corresponding to a $C$-linked pentose; therefore, compound $\mathbf{2 3}$ was identified as apigenin-6- $C$-pentoside8-C-rhamnoside.

Peak (22) and (24) at 679 and $m / z 693$ revealed the same fragment ion at $\mathrm{m} / \mathrm{z} 547$, after the loss of pentose unit [M-132-H] or rhamnose unit $[\mathrm{M}-146-\mathrm{H}]^{-}$, respectively. Both pentose and rhamnose are suggested to be attached as $O$-substitution of the flavone di $C$-glycoside structure $(\mathrm{m} / \mathrm{z} 547)$. Further fragmentation pattern of $\mathrm{m} / \mathrm{z} 547$ indicates the same structure of compound
23. Therefore, compounds 22 and 24 were similar to peak (23) with an extra mass difference of $132 \mathrm{amu}$ (pentose moiety) and $146 \mathrm{amu}$ (rhamnose moiety) in molecular ions, respectively. Therefore, compounds (22) and (24) were identified as apigenin 6- $C$-pentoside- $8-C$-rhamnose- $O$-pentoside and apigenin $6-C$-pentoside-8- $C$-rhamnose- $O$-rhamnoside, respectively.

Peak (26) $\mathrm{m} / \mathrm{z} 753$ showed a fragment ion at $\mathrm{m} / \mathrm{z}$ 591, after the loss of a dehydrated hexose unit [M-162-H] $]^{-}$, attached as $O$-substitution of the flavone di $C$-glycoside structure $(\mathrm{m} / \mathrm{z} 591)$. Further fragmentation pattern of $\mathrm{m} / \mathrm{z} 591$ was similar to that of the peak (25) with an extra mass difference of 14 amu in molecular ions and its fragment masses assigned as apigenin 6- $C$-rhamnoside-8$C$-hexoside-methyl ether (Farag et al., 2016). $C$-glycosyl apigenin methyl ether derivatives were reported previously from some monocotyledon member; Iris species (Iridaceae) (Kawase and Yagishita, 1968).

\section{In vitro cytotoxic activity}

The results indicated that the bulbs aqueous methanol extract of $D$. erythraeum showed moderate activity against MCF7 and HCT116 at $100 \mu \mathrm{g} / \mathrm{ml}$ with cell viability of $43.6 \%$ and $48.4 \%$, respectively. However, it exhibited no evident cytotoxicity against A549 and HEPG2 cell lines.

\section{CONCLUSION}

Total 22 compounds including $14 C$-glycosyl flavonoids, 6 phenolic acid derivatives (coumaric and caffeic acids derivatives), one organic acid, and one anthocyanin (delphinine derivative) were identified or tentatively characterized, all of them were detected for the first time from $D$. erythraeum. The presence of $C$-glycosyl flavonoids supported the suggestion achieved by El-Shabrawy et al. (2016), which indicate that $D$. erythraeum has a similar biosynthetic pathway and, therefore, a closer relationship with the species of Asparagaceae family than Liliaceae. Moreover, the studied extract showed moderate activity against MCF7 and HCT116 at $100 \mu \mathrm{g} / \mathrm{ml}$ with cell viability of $43.6 \%$ and $48.4 \%$, respectively.

\section{ACKNOWLEDGMENTS}

This research is funded by the National Research Centre, Cairo, Egypt; Project number 11010328. The authors also thanks Dr. El-Shabrawy M. for collecting and authenticating the plant material of the present study.

\section{CONFLICT OF INTERESTS}

Author declares that there are no conflicts of interest.

\section{REFERENCES}

Abdulkareem KA, Garuba T, Abdulrasaq R, Mustapha OT. Studies on the morphology and phytochemical constituents of Dipcadi filamentosa in two states of North-Central Nigeria. J Chem Biol Phys Sci, 2014; 4(3):2158-64.

Adly F, Moussaid M, Berhal C, Razik A, Elamrani AA, Moussaid H, Bourhim N, Loutfi M. Phytochemical screening and biological study of ethanol extractives of Dipcadi serotinum (L.) Medik. EJARBLS, 2015; $3(3): 17-23$.

Ali SI. Flora of Pakistan: hyacinthaceae. Department of Botany, University of Karachi, Karachi, Pakistan, no. 214, 2005.

Bhandari MM. Flora of the Indian Desert. Scientific Publishers, Jodhpur, India, 1990 
Boulos L. Flora of Egypt, revised annotated edition. Al Hadara Publishing, Egypt, 2009.

Dias C, Dias M, Borges C, Almoster FMA, Paulo A, Nascimento J. Structural elucidation of natural 2-Hydroxy Di- and Tricarboxilic Esters, Phenylpropanoid Esters, and Flavonoids extracted from the bulbs of Autonö madeirensis using GC-EIMS, ESIMS and MS/MS techniques. Proceeding of 21st Informal Meeting on Mass Spectrometry, Antwerp, Belgium, 11-15 May 2003, P22:118.

El-Shabrawy MO, Marzouk MM, Hosni HA, El Garf IA, Kawashty SA, Saleh NAM. Flavonoid constituents of Dipcadi erythraeum Webb. \& Berthel. Asian Pac J Trop Dis, 2016; 6(5):404-5.

El-Sherei MM, Ragheb AY, Mosharrafa SA, Marzouk MM, Kassem MES, Saleh NAM. Pterygota alata (Roxb.) R. Br. leaves and stems: chemical constituents, anti-hyperglycemic effect and anti-oxidative stress in alloxan-induced diabetic rats. J Mater Environ Sci, 2018; 9(1):245-55.

Farag MA, Rasheed DM, Kropf M, Heiss AG. Metabolite profiling in Trigonella seeds via UPLC-MS and GC-MS analyzed using multivariate data analyses. Anal Bioanal Chem, 2016; 408(28):8065-78.

Felipe DF, Brambilla LZS, Porto C, Pilau EJ, Cortez DAG. Phytochemical analysis of Pfaffia glomerata inflorescences by LC-ESIMS/MS. Molecules, 2014; 19:15720-34.

Geiger H, Markham KR. The C-glycosylflavone pattern of Passiflora incamata L. Z Naturforsch C. 1986; 41(9-10):949-50.

Hussein S, Usama EM, Tantawy M, Kawashty S, Saleh N. Phenolics of selected species of Persicaria and Polygonum (Polygonaceae) in Egypt. Arab J Chem, 2017; 10(1):76-81.

Hussein SR, Abdel Latif RR, Marzouk MM, Elkhateeb A, Mohammed RS, Soliman AAF, Abdel-Hameed ES. Spectrometric analysis, phenolics isolation and cytotoxic activity of Stipagrostis plumosa (Family Poaceae). Chem Pap, 2018; 72:29-37.

Ibrahim LF, Marzouk MM, Hussein SR, Kawashty SA, Mahmoud K, Saleh NAM. Flavonoid constituents and biological screening of Astragalus bombycinus Boiss. Nat Prod Res, 2013; 27:386-93.

Jongbloed M, Western AR, Böer B. Annotated check-list for plants in the U.A.E. Zodiac Publishing, Dubai, UAE, 2000.

Kawase A, Yagishita K. On the structure of a new C-Glycosyl Flavone Embinin, isolated from the petals of Iris germanica Linnaeous. Agric Biol Chem, 1968; 32(4):537-8.

Mabry TJ, Markham KR, Thomas MB. The systematic identification of flavonoids. Springer, Verlag, New York, NY, pp. 35-109, 1970.
Mandaville JP. Flora of Eastern Saudi Arabia. Kegan Paul Int, London, UK, 1990.

Marzouk MM, Hussein SR, Elkhateeb A, El-shabrawy M, AbdelHameed ESS, Kawashty SA. Comparative study of Mentha species growing wild in Egypt: LC-ESI-MS analysis and chemosystematic significance. J Appl Pharm Sci, 2018; 8(8):116-22.

Marzouk MM, Al-Nowaihi ASM, Kawashty SA, Saleh NA Chemosystematic studies on certain species of the family Brassicaceae (Cruciferae) in Egypt. Biochem Syst Ecol, 2010; 38:680-5.

Moussaid M, Elamrani A, Bourhim N, Benaissa M. Contribution to the study of the essential oil of Dipcadi serotinum (L.) Medik du Maroc. Afrique Sci, 2013; 9(1):34-42.

Simirgiotis MJ, Benites J, Areche C, Sepúlveda B. Antioxidant capacities and analysis of Phenolic Compounds in three endemic Nolana species by HPLC-PDA-ESI-MS. Molecules, 2015; 20:11490-507.

Spínola V, Pinto J, Castilho PC. Identification and quantification of phenolic compounds of selected fruits from Madeira Island by HPLCDAD-ESI-MSn and screening for their antioxidant activity. Food Chem, $2015 ; 173: 14-30$

Taamalli A, Arráez-Román D, Abaza L, Iswaldi I, FernándezGutiérrez A, Zarrouk M, Segura-Carretero A. LC-MS-based metabolite profiling of methanolic extracts from the medicinal and aromatic species Mentha pulegium and Origanum majorana. Phytochem Anal, 2015; 26:320-30.

Williams CA. Biosystematics of the monocotyledoneae flavonoid patterns in leaves of the liliaceae. Biochem Syst Ecol, 1975; 3(4):229-44.

How to cite this article:

Marzouk MM, Elkhateeb A, Abdel Latif RR, Abdel-Hameed ES, Kawashty SA, Hussein SR. C-glycosyl flavonoidsrich extract of Dipcadi erythraeum bulbs: Phytochemical and anticancer evaluations. J Appl Pharm Sci, 2019; 9(06): 094-098. 